\title{
Escape of protists in predator-generated feeding currents
}

\author{
Hans Henrik Jakobsen*
}

Danish Institute for Fisheries Research, Department of Marine and Coastal Ecology, Kavalergården 6, 2920 Charlottenlund, Denmark, and Marine Biological Laboratory, Strandpromenaden 5, 3000 Helsingør, Denmark

\begin{abstract}
The ciliate Strobilidium sp. and 2 flagellates, Chrysochromulina simplex and Gymnodinium sp., were exposed to predator-generated feeding currents, and their escape responses were quantified using 2- and 3-dimensional video techniques. All 3 studied organisms responded by escaping at a defined distance to their predators. A critical threshold fluid deformation rate of escape of $3.6 \mathrm{~s}^{-1}$ was estimated in a quantifiable siphon suction flow field for the ciliate Strobilidium sp. Using previous published models and the critical deformation rate estimated here, I predicted the reaction distance of Strobilidium sp. to the copepod Temora longicornis. The predicted reaction distance fit closely that measured. When the flagellates were exposed to the flow field of the ciliate Uronema filificum, they both responded up-stream to the feeding current. From the distance at which the flagellates responded to the ciliate, the critical deformation for escape for both the flagellates was estimated to range between 6.9 and $14.5 \mathrm{~s}^{-1}$. The critical deformation rate of flagellates proved to be slightly higher than that of ciliates. I speculate that this reflects that ciliates are the main predator on flagellates while ciliates themselves have a higher deformation sensitivity in order to avoid copepods that overall have a more well-developed sensory apparatus.
\end{abstract}

KEY WORDS: Escape behaviour • Feeding current • Strobilidium sp. • Temora longicornis . Chrysochromulina simplex $\cdot$ Gymnodinium sp. $\cdot$ Flagellates $\cdot$ Flow

Resale or republication not permitted without written consent of the publisher

\section{INTRODUCTION}

Protozoans such as ciliates and flagellates are important food sources for copepods (e.g. Beers \& Stewart 1967). In spite of the profound importance of protozoans, very little is known about their predator detection and predator avoidance behaviours. Jonsson \& Tiselius (1990) and Gilbert (1994) used video for direct observations of prey-predator interaction in ciliates. From these studies it was clear that ciliates respond remotely to predator-generated signals, although the properties of the signal remain unclear.

In a recent series of experiments, Jakobsen (2001) studied the escape behaviour in a range of protists exposed to an artificial flow field generated by a suc-

*Present address: Shannon Point Marine Centre, 1900 Shannon Point Road, Anacortes, Washington 98221, USA. E-mail: jakobsh@Cc.wwu.edu tion siphon. It was shown that ciliates respond to the fluid signal generated by the fluid motion towards the suction siphon. Acceleration itself was too weak to be detected by protozoans entrained in the flow, but the strain along the flow line generated by the velocity difference, termed 'deformation rate', were sufficient to produce a perceivable signal. The critical deformation threshold for escape varies between 2 and $3.5 \mathrm{~s}^{-1}$ for ciliates (Jakobsen 2001). Similarly to protozoans, copepods and nauplii respond to fluid deformation in the range 1 to $8 \mathrm{~s}^{-1}$ (Kiørboe et al. 1999, Titelman 2001).

The range of critical deformation rates for escape found in marine organisms is consistently higher than the maximum natural fluid deformation generated by ambient water motions (up to $1 \mathrm{~s}^{-1}$; Kiørboe \& Saiz 1995). At the same time the critical deformation rate for escape is typically lower than the peak deformation rate generated in the feeding currents of copepods (>5 s ${ }^{-1}$; Kiørboe \& Visser 1999). 
Jakobsen (2001) suggested that predator detection and subsequent escapes by protozoans are most efficient against predators using feeding currents such as the copepod Temora longicornis and less efficient against ambush feeding copepods such as Acartia tonsa, which generate a much lower hydromechanical signal.

Because flagellates $<10 \mu \mathrm{m}$ are sub-optimal prey for copepods (Bergreen et al. 1998) their main predators are likely to be ciliates. While copepods have a welldeveloped battery of mechanosensors that allow remote detection and location of swimming prey such as ciliates (Jonsson \& Tiselius 1990) and flagellates (Svensen \& Kiørboe 2000), most planktonic ciliates are filter feeders. Therefore, escape behaviour of ciliates and small flagellates may be different in terms of the critical deformation sensitivity.

In this study, the escape behaviour of Strobilidium sp. was examined in a 3-dimensional (3D) video set-up. The ciliate escape behaviour is described when exposed to a suction siphon flow and compared to the escape in the feeding current generated by the copepod Temora longicornis. Using a recently published model that describes the relationship between the reaction distances $\left(R_{\mathrm{def}}\right)$ of the escaping preys and feeding current velocities of stationary suspension feeders (Kiørboe \& Visser 1999), I predicted the distance to the copepod at which the ciliate would initiate an escape reaction and compared it to the actual measured distance. Also the escape behaviour of 2 flagellates, Chrysochromulina simplex and Gymnodinium sp., were studied. The flagellates were exposed to a flow generated by the sedentary ciliate Uronema filificum. Because the predicted $R_{\text {def }}$ of the model closely fit that actually measured in the copepod ciliate interaction, I also used the model to estimate the critical threshold deformation for escape in the 2 flagellates in the ciliate flow field.

\section{MATERIALS AND METHODS}

Protozoans were cultivated in growth media based on 32 PSU pasteurised Millipore filtered seawater with L-nutrients added (Guillard \& Hargraves 1993). The autotrophic flagellate cells used in the experiments were maintained at a light irradiance between 60 and $100 \mu \mathrm{mol}$ photons $\mathrm{m}^{-2} \mathrm{~s}^{-1}$ in aerated conical 21 flasks. The diatom Thalassiosira pseudonanna strain ccmp 1335 (equivalent spherical diameter [ESD] 4 $\mu \mathrm{m}$ ) was obtained from the Bigelow algae collection, and Chrysochromulina simplex stain K-0272 (ESD $\sim 4 \mu \mathrm{m}$ ) and Heterocapsa rotundata stain K-0483 (ESD 6 $\mu \mathrm{m}$ ) were kindly made available by the Scandinavian Culture Centre for Algae and Protozoa, University of
Copenhagen, Denmark. Synechococcus sp. was supplied from the culture collection of the Marine Biological Laboratory, University of Copenhagen, Denmark, and Rhodomonas salina originated from the Danish Institute for Fisheries Research's collection of algae.

Cultures of heterotrophs. The ciliate cultures were established from natural seawater sampled in the marina of Helsingør, Denmark in June or October 2000. Because the salinity at the time of sampling was $21 \mathrm{PSU}, \mathrm{I}$ increased the salinity gradually over a few days to 32 PSU. By adding the autotrophic dinoflagellate Heterocapsa rotundata to natural seawater, growth of several ciliate species was observed after approximately $1 \mathrm{wk}$. Cells of Strobilidium sp. (ESD $\sim 42 \mu \mathrm{m} ; \mathrm{N}=20$ ) were picked with a fine-drawn Pasteur pipette and transferred into the wells of a 24 well multidish (Nunc ${ }^{\mathrm{TM}}$, Nalge Nunc International, Rochester, NY, USA). Growth of the ciliate was followed over a couple of days until cell divisions were observed in several of the wells. The contents (ca $3 \mathrm{ml}$ ) of the wells with ciliates were then transferred to $50 \mathrm{ml}$ transparent culture bottles ( $\mathrm{Nunc}^{\mathrm{TM}}$ ) containing fresh growth medium and $H$. rotundata prey cells. The same procedure was used for establishing cultures of Uronema filificum (ESD 20 $\mu \mathrm{m}$ ) and Gymnodinium sp. except that other prey species were used (Synechococcus sp. and Rhodomonas salina, respectively).

A culture of the copepod Temora longicornis was established by collecting animals from $200 \mu \mathrm{m}$ net tows taken in the northern part of Øresund (the strait separating Denmark and Sweden). The animals were transferred to a 51 beaker with 32 PSU Millipore filtered seawater. The beaker was aerated at a low rate. The copepods were fed Rhodomonas salina. After approximately $1 \mathrm{mo}$, high numbers of nauplii and copopodites were observed and the culture was then diluted into a 1001 polyvinyl chloride (PVC) cylinder and maintained with $R$. salina as prey for an extended time period. The culture was maintained as described for Acartia tonsa (Støttrup et al. 1986).

Prior to video recordings copepods were fed ad libitum for $24 \mathrm{~h}$, and protists were kept well fed and in exponential growth for a least $24 \mathrm{~h}$.

Video set-up and analysis. The response of Strobilidium sp. to a siphon flow field and to the feeding current generated by the copepod Temora longicornis were studied in a set-up that allowed characterisation of motility in 3D. Viewing the escape behaviour of Strobilidium sp. in the siphon flow field allowed me to quantify the escape velocity and escape direction, and to estimate the critical deformation rate required to elicit an escape response. A detailed description of the set-up is given in Jakobsen (2001) and the theory related to the flow field generated by a suction siphon is dealt with in detail in Kiørboe et al. (1999). Briefly, 2 charge coupled device 
(CCD) cameras were viewing an aquarium at right angles (Minitron MTV-1802CD, Minitron Enterprise Co., Taipei, Taiwan). Each camera is equipped with a 105 mm macro lens (Nikon) connected to a mixer, which merges the 2 video signals, a time code generator (Panasonic WJ 180) and a VCR (Panasonic NV-FS200 HQ). Magnification is optimised for the maximum view that allows the ciliates to be recognised. Light is provided by 2 infrared light-emitting diodes placed in the focal point of 2 (diameter $16 \mathrm{~cm}$ ) lenses, creating parallel (collimated) light beams through the experimental container into each camera. Filming a small metal sphere of known diameter provided vertical and horizontal size calibration. A fine-drawn Pasteur pipette mounted on the bottom of the plexiglass container generated a radially symmetrical flow field. The water left the container through the siphon at an adjustable rate.

The videotapes were analysed frame by frame. Single video frames were converted into computer files by a DT 3152 (Data Translation, Marlboro, Massachusetts, USA) frame-grabber card mounted in an IBM personal computer using software bundled with the framegrabber card. The computer files were digitised using Image tools (UTSCHA, Image Tool ver. 2.03, developed by the University of Texas Health Science Center, San Antonio, TX, USA). The flow field was characterised by tracking neutrally buoyant pine pollen grains to the siphon tip. The hydromechanical signal perceived by protozoans is fluid deformation (Jakobsen 2001). The critical deformation rate required to initiate an escape jump was calculated from the starting position of escape jumps of Strobilidium sp. according to Kiørboe et al. (1999). A total of 104 escape events were observed. Jump velocities, jump length and escape direction were calculated from the difference between start and end position of each escape jumps. Because jump trajectories are affected by the drag of the fluid, I corrected for this according to Jakobsen (2001). Jump directions of Strobilidium sp. in the siphon flow were considered relative to gravity, where $0^{\circ}$ is down and $180^{\circ}$ is up. Jump directions were also considered relative to the suction flow. Jumps of $0^{\circ}$ are directly towards the suction source while $180^{\circ}$ jumps are away from the suction.

Adult specimens with males and females roughly in a ratio of 1:1 of the copepod Temora longicornis were collected from the laboratory culture. The copepods were added together with Strobilidium sp. to a transparent $10 \times 10 \times 10 \mathrm{~cm}$ acrylic container. The container was filmed in the 3D set-up, and interactions of Strobilidium $\mathrm{sp}$. with the feeding current of $T$. longicornis were digitised from single video frames as described above. By coordinate transformation of the Strobilidium sp.-T. longicornis interaction, data of each copepod-ciliate event could be evaluated. Using the centre between the left and right antenna as reference point, and the axis made up by the reference point and the anterior end of the prosome as the rotational axis, all the T. longicornis-Strobilidium sp. interactions considered could be viewed relative to each other in the ventral and in the medial plane of T. longicornis.

Two-dimensional (2D) video recording. Because of the small size of Chrysochromulina simplex and Gymnodinium sp., they could not be seen in the 3D set-up. Instead, escape events were filmed in 2D using an inverted microscope. The microscope was equipped with a CCD video camera (MINITRON MTV-1802CD). The video set-up was otherwise as described above.

The ciliate Uronema filificum was used to generate a flow field in which escapes of flagellates could be observed. Although this ciliate feeds on bacteria-sized prey, its feeding current is strong enough to elicit escape jumps in flagellates.

Uronema filificum may be free-swimming or feed with the caudal cilia attached to surfaces such as the inside wall of a transparent plastic NUNC flask. Only attached $U$. filificum cells were considered.

Filming in 2D instead of 3D leads to underestimation of length scales. I attempted to minimise this error by reducing the depth of field of the microscope and by considering only those particles that remained in the plane of focus.

The flow field around Uronema filificum was characterised by following non-motile Thalasiosira pseudonanna diatoms in the feeding current in the same fashion as described above for the siphon flow. U. filificum moves slightly while feeding in the attached mode. By using the oral tip-caudal base vector as a reference axis I could always orient the particle relative to $U$. filificum regardless of the ciliate's position.

The behavioural responses of the flagellates Chrysochromulina simplex and Gymnodinium sp. in the feeding current of well-fed Uronema filicoum were studied in transparent $50 \mathrm{ml}$ NUNC polystyrene bottles. The initial positions of approximately 50 encounters resulting in escapes of each species were digitised. By noting the initial jump position, the critical deformation rate could be estimated from observations of the flow field velocities and a previously published 'spherical pump model' (Kiørboe \& Visser 1999).

Critical deformation rate of prey escapes in predator feeding currents. The spherical pump may describe the feeding current generated by a stationary copepod or a sessile ciliate, and the relevant components are derived in Kiørboe \& Visser (1999). In a spherical pump, water is pumped at a uniform rate through a fixed spherical region of space. Hence, a particle entrained in such a flow experiences fluid deformation that strains the particle. The fluid deformation $(\Delta)$ generated in front of a spherical pump at a given distance to the pump is as follows: 


$$
\Delta=\frac{3 U C\left(r^{2}-C^{2}\right)}{2 r^{4}}
$$

where $r$ is the radial distance from the centre of the spherical pump to the particle, $U$ is the maximal feeding current velocity and $C$ is the radius of the pump. The maximum deformation $\left(\Delta_{\max }\right)$ experienced by the particle is found at a distance $\sqrt{2 C}$ in front of the pump and is given by the following:

$$
\Delta_{\max }=\frac{3 U}{8 C}
$$

The critical deformation rate $\left(\Delta^{*}\right)$ required to elicit an escape can be used to estimate the $R_{\text {def }}$ of the Strobilidium sp. in the feeding current to the copepod:

$$
R_{\mathrm{def}}=c \sqrt{\frac{3 U}{4 c \Delta^{*}}\left\{1+\sqrt{1-\frac{8 c \Delta^{*}}{3 U}}\right\}} \text { for } \Delta^{*} \leq \Delta_{\max }
$$

\section{RESULTS}

\section{Escape response of Strobilidium sp. in the siphon flow}

I determined the escape angles relative to the gravity in the siphon experiment (Fig. 1). I separated the escape events in the siphon flow based on the initial escape jump position into those occurring above and those below the horizontal plane relative to the siphon tip. This was done to examine the ciliate escape fixed relative to gravity. Jump direction relative to the suction flow was estimated in a similar fashion. However, no significant differences between the 2 groups were found and hence data were pooled into 1 group.

Table 1. Strobilidium sp. escape directions measured in the siphon flow. No significant difference was found between jumps initiated below and those initiated above the tip of the siphon. Consequently, all data were pooled into 1 group (lower row, 'All escape jumps'). Statistical methods used for circular data were according to Batchlet (1981)

\begin{tabular}{|lcc|}
\hline & $\begin{array}{c}\text { Escape direction }\left(^{\circ}\right) \\
\text { relative to gravity } \\
(\text { mean } \pm \mathrm{SD})\end{array}$ & $\begin{array}{c}\text { Escape direction }\left(^{\circ}\right) \\
\text { relative to suction flow line } \\
\text { (mean } \pm \text { SD) }\end{array}$ \\
\hline $\begin{array}{l}\text { Jumps initiated } \\
\text { below the siphon tip } \\
\left(0 \text { to } 90^{\circ}\right) \mathrm{N}=23\end{array}$ & $123 \pm 28$ & $54 \pm 36$ \\
$\begin{array}{l}\text { Jumps initiated above } \\
\text { the siphon tip } \\
\left(90 \text { to } 180^{\circ}\right) \mathrm{N}=81\end{array}$ & $102 \pm 36$ & $70 \pm 48$ \\
$\begin{array}{l}\text { Test used: } \\
\text { Test value: }\end{array}$ & Wheeler-Watson test \\
$\begin{array}{l}\text { All escape jumps } \\
\left(0 \text { to } 180^{\circ}\right) \mathrm{N}=104\end{array}$ & $t=0.16, \mathrm{p}<0.001$ & $\begin{array}{c}\text { Wheeler-Watson test } \\
t=0.113, \mathrm{p}<0.001 \\
707 \pm 35\end{array}$ \\
\hline
\end{tabular}
(Table 2).

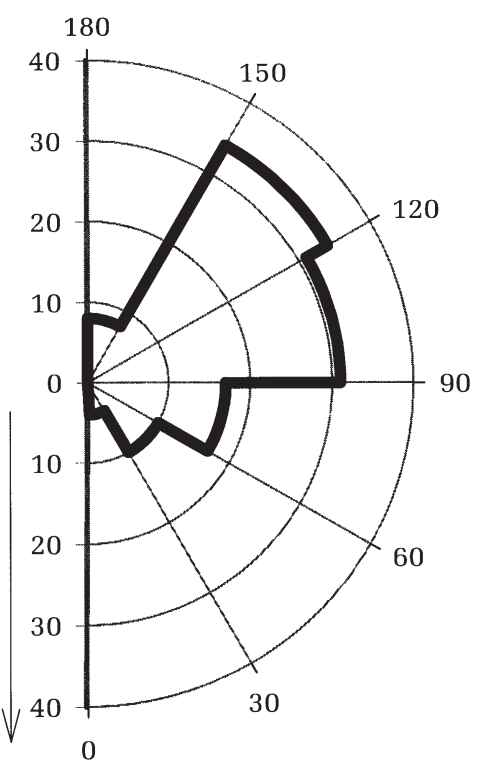

Fig. 1. Frequency distribution of Strobilidium sp. escape directions relative to gravity in the siphon flow. $180^{\circ}$ is up and $0^{\circ}$ is down

The average escape angle was $107^{\circ}$ and $72^{\circ}$ relative to gravity and suction flow, respectively (Table 1 ). The critical deformation rate of Strobilidium sp. was $3.6 \mathrm{~s}^{-1}$

\section{Strobilidium sp. response to the feeding current of Temora longicornis}

The feeding copepods were almost stationary when considered at the time scale of an encounter event with Strobilidium sp. While generating a feeding current, the copepod Temora longicornis was oriented with the dorsal side downwards and the urosome pointing downwards. During feeding the prosome axis was held in an average angle of $143^{\circ}$ relative to gravity, with the urosome bent at an angle of $26^{\circ}$ to the prosome (Table 3). Feeding in this position generates a feeding current where flow velocity increases downwards toward the mouth of the copepod. The feeding current retains prey particles which are brought into contact with the copepod and then potentially eaten. The feeding current also entrained Strobilidium sp. cells that potentially may perform escape jumps. By coordinate transforming all interactions I could view all relevant positions in either the ventral or in the medial plane (Fig. 2). The initial positions where Strobilidium sp. escaped were concentrated around the anterior end of T. longicornis, which indicates 
Table 2. Strobilidium sp. escape velocity, escape length and critical threshold deformation measured in the siphon flow. No significant difference was found between jumps initiated below and those initiated above the tip of the siphon. Consequently, all data were pooled into 1 group (lower row, 'All escape jumps')

\begin{tabular}{|c|c|c|c|}
\hline & $\begin{array}{l}\text { Critical threshold deformation rate } \\
\left(\Delta^{*} \mathrm{~s}^{-1}[95 \% \text { confidence interval] })\right.\end{array}$ & $\begin{array}{c}\text { Escape velocity } \\
\left(\times 10^{-2} \mathrm{~cm} \mathrm{~s}^{-1} \pm \mathrm{SD}\right)\end{array}$ & $\begin{array}{c}\text { Escape length } \\
\left(\times 10^{-2} \mathrm{~cm} \pm \mathrm{SD}\right)\end{array}$ \\
\hline $\begin{array}{l}\text { Initial jump initiated below the sip } \\
\left(0 \text { to } 90^{\circ}\right) \mathrm{N}=23\end{array}$ & $4.1 \mathrm{~s}^{-1}(2.1$ to 7.1$)$ & $34 \pm 21$ & $9.2 \pm 6.8$ \\
\hline $\begin{array}{l}\text { Initial jump above the siphon tip } \\
\left(90 \text { to } 180^{\circ}\right) \mathrm{N}=81 \\
\text { Test used: } \\
\text { Test value: }\end{array}$ & $\begin{array}{c}3.5 \mathrm{~s}^{-1}(2.6 \text { to } 4.5) \\
\text { Mann-Whitney rank sum } \\
\quad \mathrm{p}=0.644\end{array}$ & $\begin{array}{c}35 \pm 16 \\
t \text {-test } \\
t=-0.126, \mathrm{p}=0.90\end{array}$ & $\begin{array}{c}8.2 \pm 4.4 \\
\text { Mann-Whitney rank sum } \\
\mathrm{p}=0.944\end{array}$ \\
\hline $\begin{array}{l}\text { All escape jumps } \\
\left(0 \text { to } 180^{\circ}\right) \mathrm{N}=104\end{array}$ & $3.6 \mathrm{~s}^{-1}$ (2.8 to 4.6$)$ & $35 \pm 17$ & $8.4 \pm 5.0$ \\
\hline
\end{tabular}

Table 3. Temora longicornis spatial orientation and size of at the time when the copepod provoked an escape jump of Strobilidium sp. The length of the urosome was measured as it appeared on the video and includes the caudal setae. Angles were calculated using circular statistic as described in Batchlet (1981)

\begin{tabular}{|lcccc|}
\hline $\begin{array}{l}\text { Antenna span } \\
\left(\times 10^{-2} \mathrm{~cm} \pm \mathrm{SD}\right)\end{array}$ & $\begin{array}{c}\text { Prosome length } \\
\left(\times 10^{-2} \mathrm{~cm} \pm \mathrm{SD}\right)\end{array}$ & $\begin{array}{c}\text { Prosome orientation } \\
\left({ }^{\circ}, \pm \mathrm{SD}\right)\end{array}$ & $\begin{array}{c}\text { Urosome length } \\
\left(\times 10^{-2} \mathrm{~cm} \pm \mathrm{SD}\right)\end{array}$ & $\begin{array}{c}\text { Urosome orientation } \\
\left({ }^{\circ}, \pm \mathrm{SD}\right)\end{array}$ \\
\hline $14.5 \pm 0.024$ & $8.1 \pm 0.02$ & $143 \pm 17$ & $9.7 \pm 1.6$ & $117 \pm 19$ \\
\hline
\end{tabular}

that the ciliates responded up-stream to the feeding current (Fig. 2).

Observations of the ciliate interaction with the copepod feeding current in 2D after data were coordinatetransformed revealed that the ciliates responded and escaped within a range of apparent distances relative to the feeding copepod (Fig. 2). The feeding copepod did not react to the escaping Strobilidium sp. Also, non-escaping ciliate cells that were brought into physical contact with Temora longicornis did not initiate any response of the copepods.

Strobilidium sp. jumped negatively geotactic in the same pattern as in the siphon flow (Fig. 3a, Table 1 vs Table 4). Because of the non-random orientation of the feeding Temora longicornis, the ciliate Strobilidium sp. jumped with a defined angle to the body of $T$. longicornis (Fig. 3b, Table 4). However, when the initial jump positions were considered relative to the horizontal plane, the jumps in the copepod feeding current were random (Fig. 3c, Table 3).

The average $R_{\text {def }}$ of Strobilidium sp. to the copepod was estimated as the distance between the initial escape jump position and the point where the feeding current velocity of Temora longicornis peaked. This point is located ventral to the $T$. longicornis body at a distance about $2 / 3$ of the cephalothorax width below the reference point between the left and right antennae (Kiørboe et al. 1999 interpreted from data from Strickler 1985 and Paffenhöfer \& Lewis 1990). The average $R_{\text {def }}$ was $6.2 \times 10^{-2} \mathrm{~cm}$ (Table 4 ) and normally distributed (Kolmogorov-Smirnov [K-S] $\alpha=0.05, \mathrm{~K}-\mathrm{S}=0.101, \mathrm{p}>$ $0.200)$, which indicates that the escape is initiated by a defined threshold signal.

The escape velocity of Strobilidium sp. in the feeding current of Temora longicornis was slightly higher than in the siphon flow (Mann-Whitney rank sum test $t=$
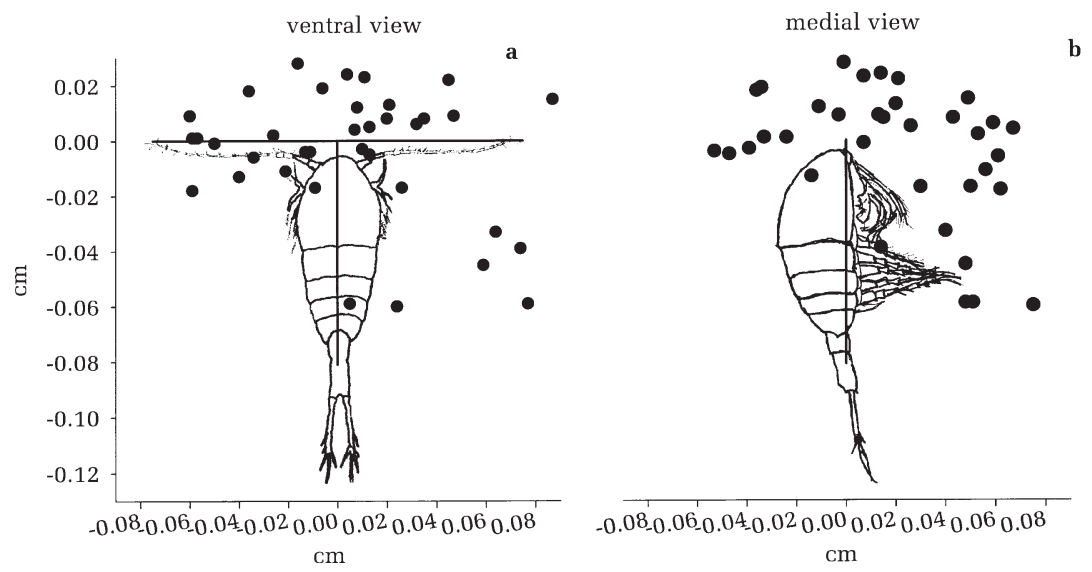

Fig. 2. Strobilidium sp. initial escape positions in the feeding current of Temora longicornis. Positions are plotted in either (a) the ventral or (b) the medial plane relative to the copepod 


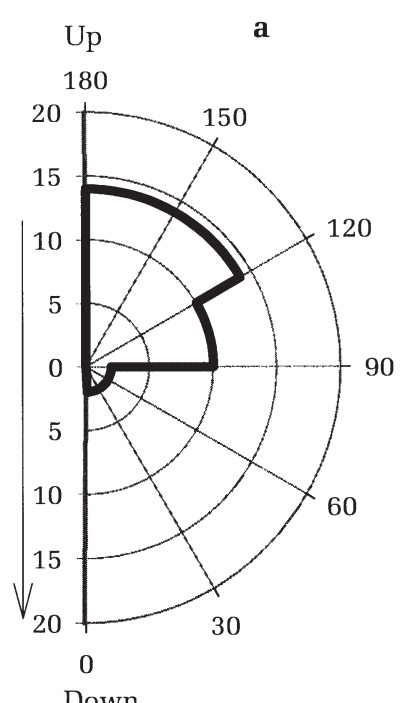

Down

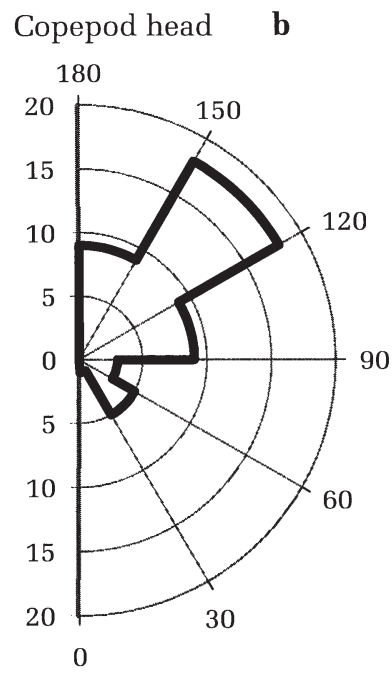

Prosome end
Ventral side of Temora longicornis

C

Fig. 3. Strobilidium sp. escape jump frequency distribution in the feeding current of Temora longicornis. Jump directions are relative to (a) gravity, (b) the prosome axis of Temora longicornis (see text) and (c) the horizontal plane

Table 4. Escape parameters of Strobilidium sp. in a Temora longicornis feeding current. Average angles were calculated according to the recommendation given in Batchlet (1981)

Escape direction $\left({ }^{\circ}\right)$ relative to gravity
$\begin{aligned} & \text { Escape direction }\left({ }^{\circ}\right) \text { relative to prosome axis } \\ & \text { (see Fig. 3a) }(\text { mean } \pm \mathrm{SD})\end{aligned}$
(see Fig. 3b) $($ mean $\pm \mathrm{SD})$ $130 \pm 37$

Non-random $\chi_{5}^{2}=24.2$;

$\alpha=0.05, \mathrm{p}<0.001$

Strobilidium sp. escape velocity $\left(\times 10^{-2} \mathrm{~cm} \pm \mathrm{SD}\right)$

$41 \pm 16$

$$
\begin{gathered}
\text { Non-random } \chi_{5}^{2}=24.5 \\
\alpha=0.05, \mathrm{p}<0.001
\end{gathered}
$$

Escape length of Strobilidium sp.

$$
\left(\times 10^{-2} \mathrm{~cm} \pm \mathrm{SD}\right)
$$

$7.8 \pm 06.1$
Escape direction $\left({ }^{\circ}\right)$ viewed in the horizontal plane (see Fig. 3c) (mean \pm SD)

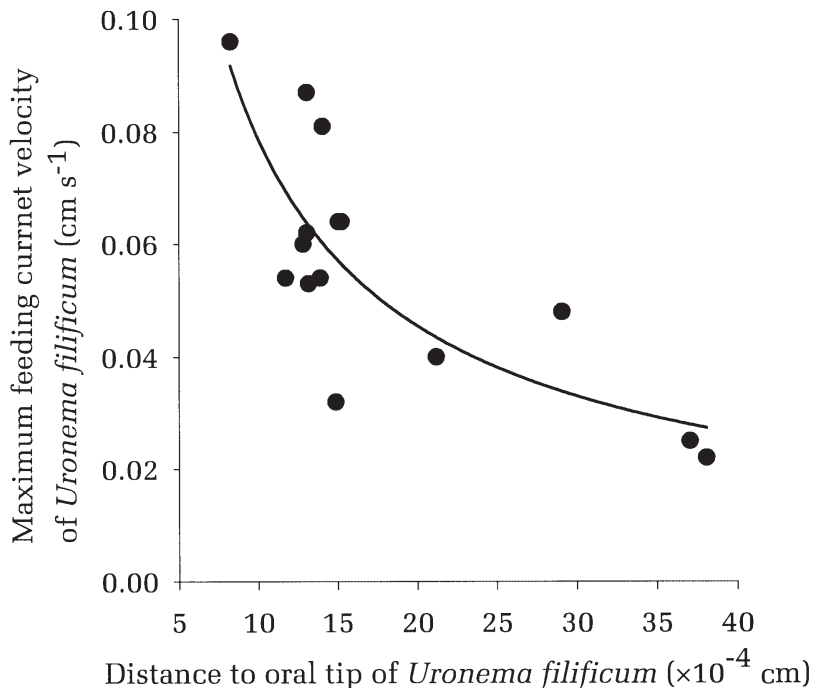

Fig. 4. Uronema filificum maximal current velocity as a function of the distance to the oral tip of the ciliate
5969.5, $\mathrm{p}<0.001$ ): $0.35 \mathrm{~cm} \mathrm{~s}^{-1}$ and $0.41 \mathrm{~cm} \mathrm{~s}^{-1}$, respectively (Tables $2 \& 4$ ). A comparison of jump lengths and escape angles relative to gravity of Strobilidium sp. yielded no significant differences (Mann-Whitney rank sum test $t=2996, \mathrm{p}=0.118$ and Wheeler-Watson $t=$ $0.172, \mathrm{p}>0.001$, respectively) between responses to the copepod feeding current and the siphon flow.

\section{Flagellate response in Uronema filificum feeding current}

The maximum flow velocity generated by Uronema filificum increased with decreasing distance to the oral tip (Fig. 4) with maximum feeding current velocity of $0.096 \mathrm{~cm} \mathrm{~s}^{-1}$. Assuming that the feeding current is radially symmetrical, I mirrored the streamlines over the oral tip-caudal cilia base axis. An isopleth diagram of feeding velocities of $U$. filificum was created using 
Surfer software (Golden Software, Golden, Colorado, USA) (Fig. 5). The flagellates Chrysochromulina simplex and Gymnodinium sp. responded up-stream in the feeding current of $U$. filificum by performing distinct jumps (Fig. 6). The response consisted of a change in direction of movement and a drastic increase in swimming velocities (Figs 7 \& 8). Subsequently, the escape velocity decreased gradually towards normal swimming speeds of both Chrysochromulina simplex and Gymnodinium sp. (Fig. 8).

The average $R_{\text {def }}$ s of the flagellates, measured from the oral tip of Uronema filificum, were both normally distributed (K-S $\alpha=0.05$, Gymnodinium sp.: K-S = $0.100, \mathrm{p}>0.200$; Chrysochromulina simplex: K-S = $0.122, p=0.065)$ and were significantly different between the 2 flagellates $(t$-test, $t=2.542, \mathrm{df}=95, \mathrm{p}=$ 0.013).

Because $R_{\text {def }}$ in the 2 flagellates differed, the corresponding critical deformation rates for escape calculated from Eq. (1) yielded a higher sensitivity (lower $\Delta^{*}$ ) in Chrysochromulina simplex than in Gymnodinium sp. (Table 5).

\section{DISCUSSION}

\section{Strobilidium sp. escape in the siphon flow}

Escape jumps, as it appeared in all the studied organisms, involves a change in swimming direction followed by a drastic increase in swimming velocity. Naitoh \& Eckert (1969) discovered the bipolar nature of Paramecium sp. cell membrane and suggested a model for coupling mechanoreception and swimming behaviour. The mechanoreceptors are embedded in

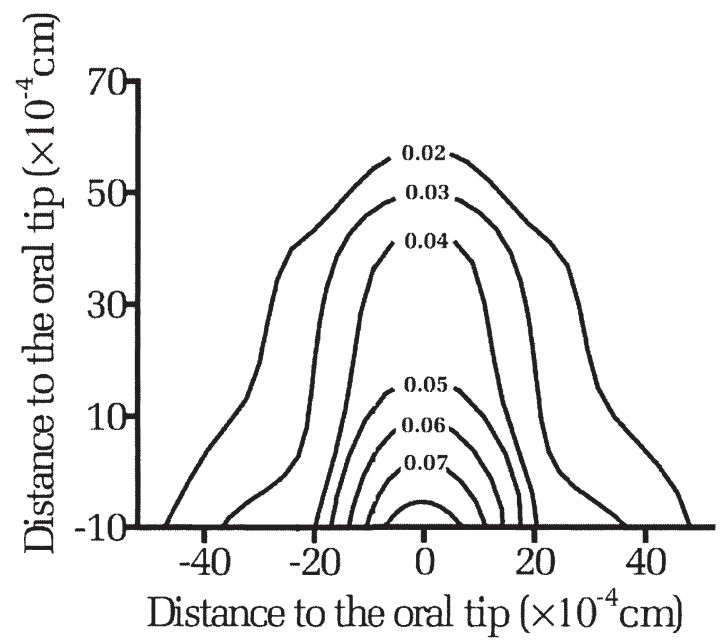

Fig. 5. Contour plot of the feeding current velocity around the oral tip of Uronema filificum. Numbers on the plot are flow velocities in $\mathrm{cm} \mathrm{s}^{-1}$
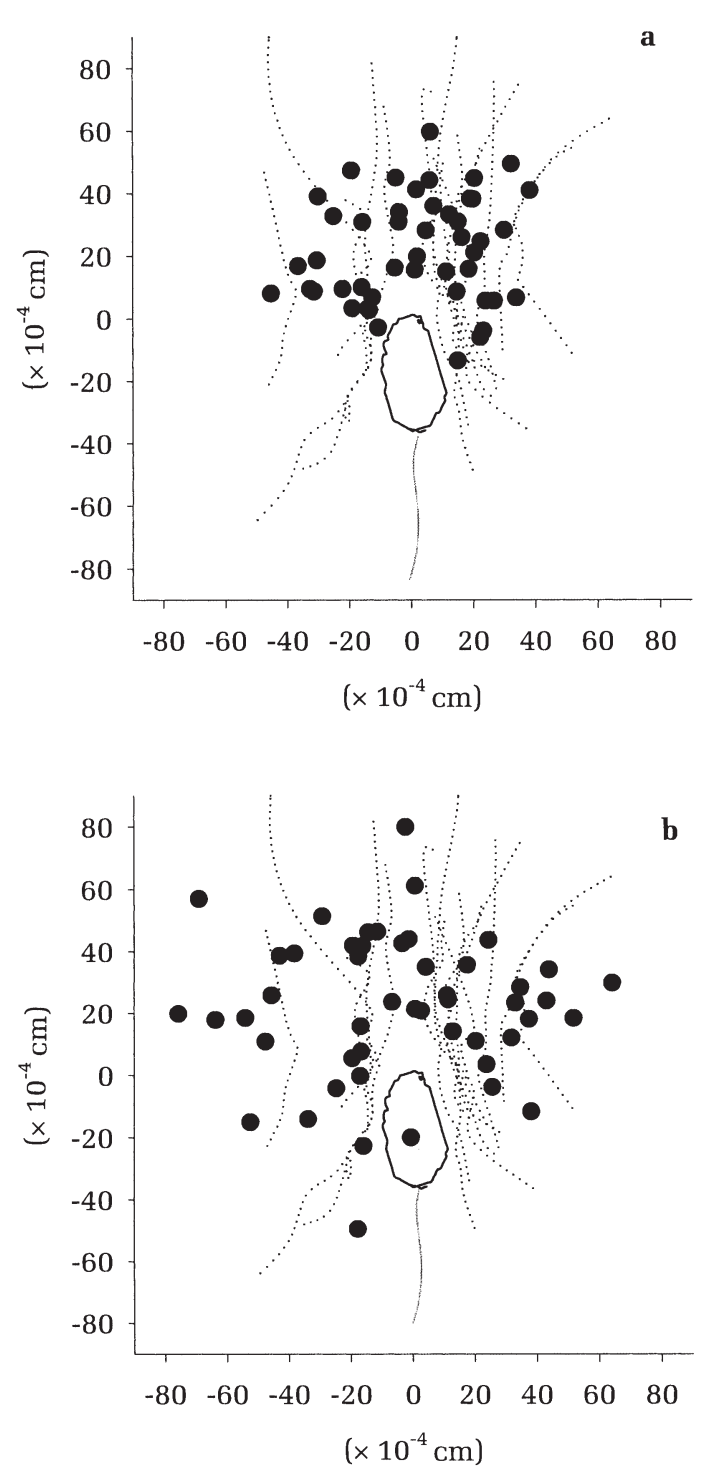

Fig. 6. The ciliate Uronema filificum showed with its feeding current (dotted lines) and initial escape positions of (a) Gymnodinium sp. and (b) Chrysochromulina simplex relative to the ciliate. All positions are viewed relative to the oral tip of the ciliate (point 0,0 ), and they represent measurement obtained for video recordings

the membrane of the cell (see review by Machemer \& Dietmer 1985). In the model of Naitoh \& Eckert (1969) the posterior mechanoreceptors depolarise the cell, inducing a change in beat direction of the cilia followed by a change in swimming direction of the cell. On the other hand, when the anterior mechanoreceptors were activated, the cell hypopolarised, increasing the cilia beat frequency and thus accelerating the swimming velocity. Escape jumps in ciliates are initiated by a defined fluid threshold (Jakobsen 2001). The fluid deformation may uniformly stretch the entire protist cell, hence activating both the posterior and the 


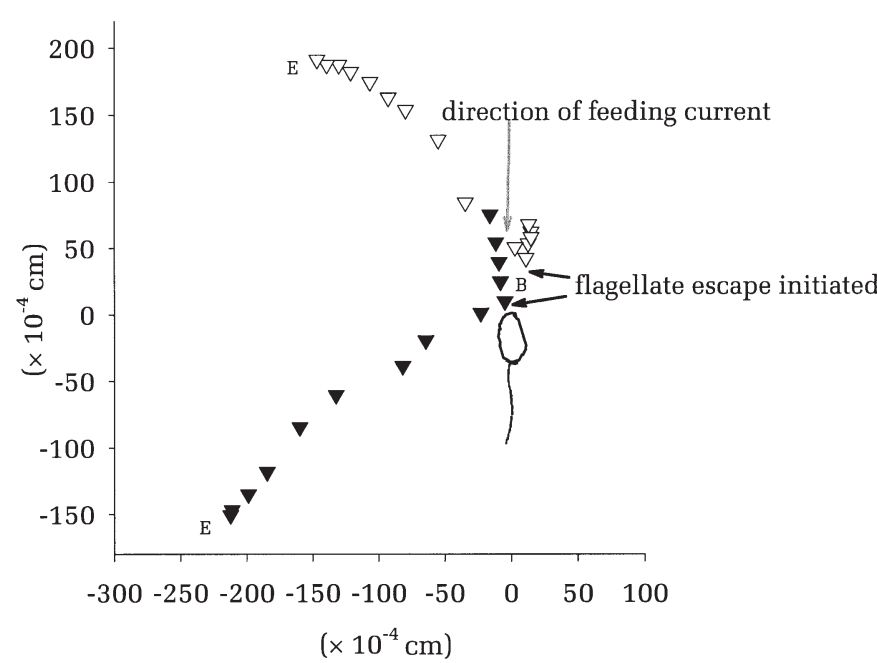

Fig 7. Examples of escape paths of flagellates in the feeding current of Uronema filificum. The origin $(0,0)$ marks the position of the oral tip of Uronema filificum. Flagellate positions are shown with equidistant time intervals (0.08 s). Closed symbols are Chrysochromulina simplex and open symbols are Gymnodinium sp. The flagellates detect the flow field (direction shown with a grey arrow) at point $B$, where they change swimming direction, accelerate and end their jump trajectories at point $\mathrm{E}$

anterior mechanoreceptors and changing the cell membrane potential almost simultaneously, inducing a shift in the cilia beat direction and frequency. Employing at the same time bipolar mechanoreceptors in escapes may affect the ability of the ciliate to perceive the directionality of the fluid deformation source because deformation is caused by a simultaneous activation of uniform stretch of the whole cell body.

Gravity is assumed to be an important force that guides the beat direction of the cilia and hence determines the vertical orientation in ciliates such as Paramecium sp. (reviewed in Machemer 2001). In this study, the escape direction appears to be guided with a gravitational component with an overall jump angle relative to gravity of $107^{\circ}$ regardless of the direction of the fluid mechanical stimuli (Table 1). This finding is similar to the escape jump direction found recently in other ciliates (Jakobsen 2001). This implies that the ciliates jump against gravity regardless of the orientation of a potential predator.

The studied ciliate escape jump was non-random relative to the flow line with an angle of $72^{\circ}$. Intuitively an escape angle $>90^{\circ}$ appears to be the most efficient escape direction since it guides the prey away from the predator. However, escape angles close to $180^{\circ}$ increase the risk of remaining in

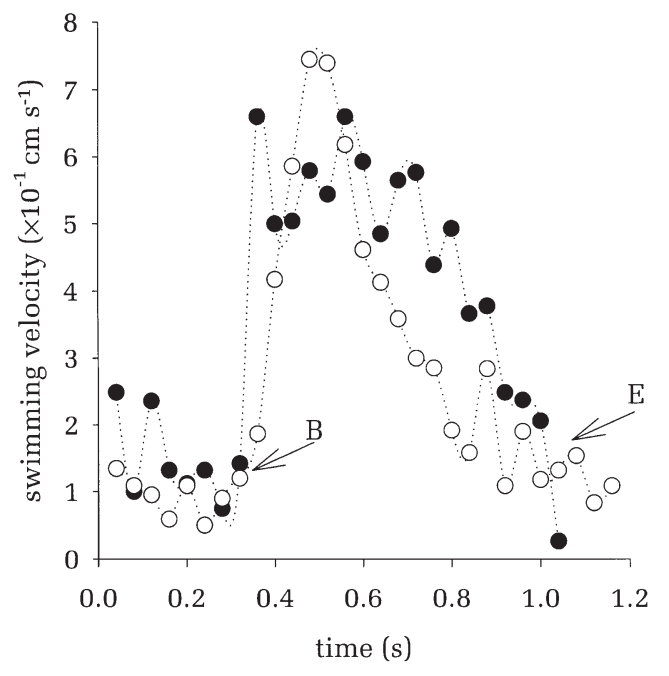

Fig. 8. Time course of escape swimming velocity in escaping flagellates. Closed symbols are Chrysochromulina simplex and open symbols are Gymnodinium sp. B and E note beginning and end of jump trajectories, respectively

the flow and subsequently suck the ciliate into contact with the feeding copepod (Jakobsen 2001). Hence, the optimal escape direction relative to the flow must be somewhere around $90^{\circ}$. The underlying mechanism responsible for guiding the escape jumps relative to the flow line is at present not clear, although passive orientation of the cell along the flow line due to asymmetrical properties of the ciliate cell could be a possible mechanism.

\section{Predator-prey interactions between ciliates and copepods}

Inter- and intraspecific variations in flow velocities and in the shapes of the flow fields of copepods exist (Tiselius \& Jonsson 1990, Bundy \& Paffenhöfer 1996). Feeding current generating copepods such as Temora longicornis typically are oriented with the anterior end upwards while water is pumped downwards, generating a funnel-shaped flow field (Tiselius \& Jonsson

Table 5. Average $( \pm \mathrm{SD})$ reaction distance $\left(R_{\text {def }}\right)$ measured in the flagellates Chrysochromulina simplex and Gymnodinium sp. to the oral tip of the ciliate Uronema filificum and the corresponding critical deformation rate of escape calculated from Eq. (1)

\begin{tabular}{|lcc|}
\hline & $\begin{array}{c}\text { C. simplex } \\
\mathrm{N}=49\end{array}$ & $\begin{array}{c}\text { Gymnodinium sp. } \\
\mathrm{N}=48\end{array}$ \\
\hline $\begin{array}{l}R_{\mathrm{def}}\left(\mathrm{cm} \times 10^{-4}\right) \\
\begin{array}{l}\text { Critical threshold deformation rate } \\
\left(\mathrm{s}^{-1}[95 \% \text { confidence interval }]\right)\end{array}\end{array}$ & $\begin{array}{c}43 \pm 18 \\
(6.9 \text { to } 10.6)\end{array}$ & $\begin{array}{l}34 \pm 16 \\
(9.6 \text { to } 14.5)\end{array}$ \\
\hline
\end{tabular}


1990, Bundy \& Paffenhöfer 1996). The flow field of feeding current generating copepods such as T. longicornis may be formalised using Eq. (1). Several studies have described the flow field of T. longicornis (Tiselius \& Jonsson 1990, Yen \& Fields 1992, Van Duren et al. 2000). Although the latter 2 studies used copepods that were tethered, the estimated maximum flow field rate may be close to the natural value since the copepods were almost stationary during interactions with prey (tethered by gravity). Reported maximal feeding current velocities were $2 \times 10^{-1}, 3 \times 10^{-1}$ and $8.5 \times 10^{-1} \mathrm{~cm}$ $\mathrm{s}^{-1}$ in Tiselius \& Jonsson (1990), Yen \& Fields (1992) and Van Duren et al. (2000), respectively. These variations may reflect the variation of the adult male and female copepods I used in the present study.

To estimate the $\mathrm{R}_{\mathrm{def}}$ of Strobilidium $\mathrm{sp}$. in the Temora longicornis feeding current, I used the critical deformation rate for escape determined in the siphon flow experiment and Eq (1). Using the values of maximal flow field velocity from the references above, Eq. (1) predicts that Strobilidium sp. responds at distances between $3.2 \times 10^{-2}$ and $9.5 \times 10^{-2} \mathrm{~cm}$ to the point of maximal feeding current velocity. Although the spherical model may be a crude estimate of the delicate flow field structure of copepods, the average $R_{\text {def }}$ of 0.062 $\mathrm{cm}$ measured in this study corresponds with that predicted from Eq. (1) (Table 4), suggesting that the spherical pump model is a useful tool in examining flow fields of feeding current predators such as T. longicornis.

The escape of the ciliate did not trigger any attack response in Temora longicornis in any of the interactions viewed. This is in contrast to other studies on interactions between copepods and their prey, in which prey escape responses elicit an attack response from the predator (Yen \& Strickler 1996). A possible explanation for the lack of a copepod attack response may be that the hydromechanical signals generated by the escaping Strobilidium sp. are too weak to be detected and the fact that $T$. longicornis has a low sensitivity to motile preys. A self-propelled particle moving in a fluid generates an anterior fluid wake (reviewed by Visser 2001). The mechanosensitive setae on the antennae of copepods can potentially sense such a wake and warn the predator about the presence and the spatial location of the prey (Yen et al. 1992). The prey size, prey swimming velocity and distance to the copepod at which the prey escapes determine the magnitude of the wake signal perceived by the copepod (Kiørboe \& Visser 1999). Using the model suggested by Visser (2001), I could estimate a maximum wake velocity of $13 \times 10^{-4} \mathrm{~cm} \mathrm{~s}^{-1}$ that $T$. longicornis perceives from the escaping Strobilidium sp. This velocity is lower than the threshold signal of $40 \times 10^{-4}$ $\mathrm{cm} \mathrm{s}^{-1}$ required to elicit an attack of the copepod
Oithonas similis (Svensen \& Kiørboe 2000) and lower than the neurological sensitivity of $20 \times 10^{-4} \mathrm{~cm} \mathrm{~s}^{-1}$ found by Yen et al. (1992) in the copepod Labidocera madurae. However, if the copepod did not feed using a feeding current and hence did not generate any fluid deformation, then the outcome of the interaction could have been different. Assuming a copepod with a raptorial ambush predator strategy, the detection distance of the ciliate would have been reduced due to the absence of a feeding current and hence a much weaker hydromechanical signal generated by the sinking copepod. If the detection distance to the copepod is, say, $2 \times 10^{-2} \mathrm{~cm}$ before the ciliate attempts an escape, then the wake velocity generated by the escaping ciliate would have reached $62 \times 10^{-4} \mathrm{~cm} \mathrm{~s}^{-1}$, which may be sufficient for copepod prey detection.

\section{Ciliate interactions with other heterotrophic protozoans}

Predators other than copepods feed on ciliates in the marine environment. Examples include dinoflagellates like Ceratium furca, Gyrodinium uncatenum and Gymnodinium sanguineum, and these may have a substantial impact on ciliates such as members of the genus Strobilidium (Bockstahler \& Coats 1993). Because prey encounter rate in a cruising predator is determined by the product of the swimming velocity and cell radius squared (encounter $=U \times c^{2}$ ) and the maximum threshold deformation generated increases with swimming velocity and decreases with cell size (Eq. 2), this type of predator behaviour favours large and slowly swimming predator cells. Dinoflagellates such as Dinophysis sp. swim relatively slower than other dinoflagellates (Buskey et al. 1993); hence, they generate relatively less ambient hydromechanical disturbance. The dinoflagellate Dinophysis rotundata ( $C=$ $22 \times 10^{-4} \mathrm{~cm}$ ) preys on ciliates (Hansen 1991) and swims rather slowly $\left(U=150 \times 10^{-4} \mathrm{~cm} \mathrm{~s}^{-1}\right.$, data for $D$. ovum in Buskey et al. 1993). Thus, the maximum deformation generated estimated from Eq. (2) is $2.6 \mathrm{~s}^{-1}$, which is close to the threshold deformation sensitivity of ciliates (Jakobsen 2001, this study). Therefore, such big and slowly swimming predators may approach protozoans unnoticed.

\section{Escape response of flagellates in the feeding current of Uronema filificum}

I also applied the spherical pump model to characterise the flow and the fluid deformation generated by feeding Uronema filificum. The estimated flow field resembled the ideal model (Fig. 5 vs Fig. 3a in Kiørboe 
Table 6. Literature data on feeding current velocities generated by suspension feeding protozoans. Reaction distance is calculated from Eq. (1) assuming a critical deformation rate corresponding to that of Chrysochromulina simplex of $8.9 \mathrm{~s}^{-1}$. Maximal deformation is calculated accordingly to Eq. (2). Escape time is the time between predator detection and actual physical predator contact assuming no avoidance reaction; see text form details on calculation. ESD: Equivalent spherical diameter

\begin{tabular}{|c|c|c|c|c|c|c|}
\hline $\begin{array}{l}\text { Feeding current } \\
\text { generating species }\end{array}$ & $\begin{array}{l}\text { Protozoan cell } \\
\text { radius; ESD } \\
(\mathrm{cm})\end{array}$ & $\begin{array}{l}\text { Maximal feeding } \\
\text { current velocity } \\
\left(\mathrm{cm} \mathrm{s}^{-1}\right)\end{array}$ & $\begin{array}{c}\text { Maximal } \\
\text { deformation } \\
\left(\mathrm{s}^{-1}\right)\end{array}$ & $\begin{array}{c}\text { Reaction } \\
\text { distance }\left(R_{\mathrm{def}}\right) \\
(\mathrm{cm})\end{array}$ & $\begin{array}{l}\text { Escape } \\
\text { time } \\
(\mathrm{s})\end{array}$ & Source \\
\hline Uronema marinum & $5 \times 10^{-4}$ & $1 \times 10^{-1}$ & 75.0 & $28.6 \times 10^{-4}$ & $1.48 \times 10^{-1}$ & Fenchel (1986) \\
\hline Vorticell elongata & $5 \times 10^{-4}$ & $7 \times 10^{-2}$ & 52.5 & $23.7 \times 10^{-4}$ & $2.12 \times 10^{-1}$ & Fenchel (1986) \\
\hline Cyclidium glauconema & $3.5 \times 10^{-4}$ & $1.7 \times 10^{-2}$ & 18.1 & $9.24 \times 10^{-4}$ & $7.65 \times 10^{-1}$ & Fenchel (1986) \\
\hline Colpidium campylum & $10 \times 10^{-4}$ & $5 \times 10^{-2}$ & 18.8 & $27 \times 10^{-4}$ & $1.82 \times 10^{-1}$ & Fenchel (1986) \\
\hline Halteria grandinella & $10 \times 10^{-4}$ & $4 \times 10^{-2}$ & 15.0 & $23.5 \times 10^{-4}$ & $2.26 \times 10^{-1}$ & Fenchel (1986) \\
\hline Diaphanoeca grandis & $2.5 \times 10^{-4}$ & $2.9 \times 10^{-2}$ & 43.5 & $11 \times 10^{-4}$ & $6.52 \times 10^{-1}$ & Fenchel (1986) \\
\hline Uronema filificum & $10 \times 10^{-4}$ & $9.6 \times 10^{-2}$ & 36.0 & $39 \times 10^{-4}$ & $9.50 \times 10^{-2}$ & This study \\
\hline
\end{tabular}

\& Visser 1999). Therefore, I used Eq. (1) to estimate the critical threshold deformation rate for escapes of the flagellates. Both of the flagellate species responded to the ciliate feeding current at critical deformation rates between 8.4 and $12.3 \mathrm{~s}^{-1}$ (Table 5). Although these rates are higher than those found for ciliates, they are still within the window defined by the physical and biological constraints in the planktonic environment (Kiørboe et al. 1999).

Jakobsen \& Hansen (1997) offered Gymnodinium sp. as prey to the planktonic ciliate Balanion comatum that feeds optimally on particles with a size close to that of Gymnodinium sp. In the same fashion, Gilbert (1994) fed a non-jumping and a jumping ciliate to a rotifer. Together these 2 studies consistently found that jumping of protozoans appeared to enhance survival against feeding current generating predators.

The maximum deformation rates generated by various protozoans have been estimated from literature observations of their feeding current velocities using Eq. (3) (Table 6). The maximum deformation rate generated by the Uronema filificum feeding current was estimated to be $36 \mathrm{~s}^{-1}$ and is within the range found in other protozoans. The maximum deformation rates generated by ciliates are of similar magnitude or even higher than the deformation generated by copepods (Kiørboe et al. 1999). The studied flagellates have a lower sensitivity to fluid deformation than ciliates (Jakobsen 2001); hence, they are well protected from initiating inordinate escape responses to ambient turbulence. However, their sensitivity is sufficient to detect ciliates and their escape velocities significantly exceed ciliate feeding current velocities (cf. Table 6). The peak deformation rate generated in the feeding current of copepods like Temora longicornis (using feeding current velocities of Tiselius \& Jonsson 1990, Yen \& Fields 1992 and Van Duren 2000) ranges between 1.6 and $6.7 \mathrm{~s}^{-1}$. These deformation rates are almost too low to trigger an escape response of the flagellates studied, and it is possible that flagellates cannot avoid feeding currents generated by copepods. However, due to the small size of Chrysochromulina simplex and Gymnodinium sp., they cannot be handled efficiently by copepods (Bergreen et al. 1988). Thus, the different threshold sensitivities of the studied flagellates and ciliates may reflect the fact that ciliates and flagellates encounter predators with different sensory capabilities. Ciliates are fed upon by copepods with a well-developed set of mechanosensors on their antenna, while ciliates eat flagellates entrained in their feeding current. Only a few studies have demonstrated behaviour in ciliates that relates to predator-prey encounters (Buskey \& Stoecker 1989, Stoecker et al. 1995). However, ciliates appear not to sense their prey remotely. Hence, flagellate preys can allow themselves the luxury of low critical deformation rate sensitivities.

The magnitude of the threshold deformation sensitivity in flagellates may be governed by the time it takes from predator detection to physical encounter if the prey does not attempt to escape 'escape time'. This escape time can be estimated by integrating the velocity function for the flow in front of the spherical pump (Eqs [1] \& [2] in Kiørboe \& Visser 1999) using a RungeKutta method for differential equations. For a flagellate with a threshold deformation sensitivity of $8.4 \mathrm{~s}^{-1}$, Table 6 summarises the worst-case scenario escape times calculated directly in front of the feeding ciliate. The escape time is $>0.1 \mathrm{~s}$ in all the considered cases, which is sufficient to bring the flagellates up to maximal speed (Fig. 8) and out of reach of the protozoans.

Acknowledgements. Thanks are given to Andy Wisser (AW) for help with coordinate transformations of Strobilidium sp.Temora longicornis interactions and with the Runge-Kutta differentiating of the pumping sphere model. Also thanks are given to Thomas Kiørboe (TK) and AW for invaluable help and discussions, and to Josefin Titelman for improving the linguistic style. This work was supported by a grant to TK from the Danish National Science Research Council \#9801391. 


\section{LITERATURE CITED}

Batchlet E (1981) Circular statistics in biology. London, Academic Press

Beers JR, Stewart GL (1967) Micro-zooplankton in the euphotic zone at five locations across the California current. J Fish Res Board Can 24:2053-2068

Bergreen U, Hansen B, Kiørboe T (1988) Food size spectra, ingestion and growth of the copepod Acartia tonsa during development: implication for determination of copepod production. Mar Biol 99:341-352

Bockstahler KR, Coats DW (1993) Spatial and temporal aspects of mixotrophy in Chesapeake Bay dinoflagellates. J Eukaryot Microbiol 41:49-60

Bundy MH, Paffenhöfer GA (1996) Analysis of flow fields associated with freely swimming calanoid copepods. Mar Ecol Prog Ser 133:99-113

Buskey EJ, Stoecker DK (1989) Behavioral responses of the marine tintinnid Favalla sp. to phytoplankton: influence of chemical, mechanical and photic stimuli. J Exp Mar Biol Ecol 123:1-16

Buskey EJ, Coulter C, Strom SL (1993) Locomotory patterns of microzooplankton: potential effects on food selectivity of larval fish. Bull Mar Sci 53:29-43

Fenchel T (1986) Protozoan filter feeding. Prog Protozool 1: 65-113

Gilbert JJ (1994) Jumping behaviour in the oligotrich ciliates Strobilidium velox and Halteria grandinella, and its significance as defence against rotifer predators. Microb Ecol 27:189-200

Guillard RRL, Hargraves PE (1993) Strichochrysis immibilis is a diatom, not a chrysophyte. Phycologia 32:234-236

Hansen (1991) Dinophysis: a planktonic dinoflagellate genus which can act both as a prey and a predator of a ciliate. Eur J Protistol 69:201-204

Jakobsen HH (2001) Escape response of planktonic protists to fluid mechanical signals. Mar Ecol Prog Ser 214: $67-78$

Jakobsen HH, Hansen PJ (1997) Prey size selection, grazing and growth response of the small heterotrophic dinoflagellate Gymnodinium sp. and the ciliate Balanion comatum: a comparative study. Mar Ecol Prog Ser 158:75-86

Jonsson PR, Tiselius P (1990) Feeding behaviour, prey detection and capture efficiency of copepod Acartia tonsa feeding on planktonic ciliates. Mar Ecol Prog Ser 60:35-44

Kiørboe T, Saiz E (1995) Planktivorous feeding in calm and turbulent environments, with emphasis on copepods. Mar Ecol Prog Ser 122:135-145

Kiørboe T, Visser AW (1999) Predation and prey perception in copepods due to hydrochemecanical signals. Mar Ecol

Editorial responsibility: John Dolan,

Villefranche-sur-Mer, France
Prog Ser 179:81-95

Kiørboe T, Saiz E, Visser AW (1999) Hydrochemecanical signal perception in the copepod Acartia tonsa. Mar Ecol Prog Ser 179:97-111

Machemer H (2001) The swimming cell and its world: structures and mechanisms of orientation in protists. Eur $\mathrm{J}$ Protistol 37:3-14

Machemer H, Deitmer JW (1985) Mechanoreception in ciliates. In: Autrum $\mathrm{H}$ (ed) Progress in sensory physiology. Springer, Berlin, p 81-118

Naitoh Y, Eckert R (1969) Ionic mechanisms controlling behavioral responses of Paramecium to mechanical stimulation. Science 164:963-965

Paffenhöfer GA, Lewis KD (1990) Perceptive performance and feeding behavior of calanoid copepods. J Plankton Res 12:933-946

Stoecker DK, Gallager SM, Langdon CJ, Davis LH (1995) Particle capture by Favella sp. (Ciliata, Tintinnina). J Plankton Res 17:1105-1124

Stottrup J, Richardson K, Kirkegaard E, Pihl NJ (1986) The cultivation of Acartia tonsa Dana for use a live food source for marine fresh larvae. Aquaculture 52:87-96

Strickler JR (1985) Feeding currents calanoid copepods: two new hypotheses. In: Laverack MS (ed) Physiological adaptations in marine animals. Symp Soc Exp Biol 89:459-485

Svensen C, Kiørboe T (2000) Remote prey detection in oithonas similis: hydromechanical vs chemical cues. J Plankton Res 22:1155-1166

Tiselius P, Jonsson PR (1990) Foraging behaviour of six calanoid copepods: observations and hydrodynamic analysis. Mar Ecol Prog Ser 66:23-33

Titelman (2001) Swimming behaviour of copepod nauplii: implications for predator-prey interactions among copepods. Mar Ecol Prog Ser 213:203-213

Van Duren L (2000) Moving (in) water: behavioural kinematics, hydrodynamics and energetics of the calanoid copepod Temora longicornis. PhD thesis, University of Groeningen, Haren

Visser AW (2001) Hydromechanical signals in the plankton. Mar Ecol Prog Ser 221:1-24

Yen J, Fields DM (1992) Escape response of Acartia hudsonica (Copepoda) naupli from the flow field of Temora longicornis (Copepoda). Arch Hydrobiol Beih Ergebn Limnol 36:123-134

Yen J, Strickler JR (1996) Advertisement and concealment in the plankton: what makes a copepod hydrodynamically conspicuous? Invertebr Biol 115:191-205

Yen J, Lenz PH, Gassie DV, Hartline DK (1992) Mechanoreception in marine copepods: electrophysiological studies on the first antennae. J Plankton Res 14:495-512

Submitted: June 15, 2001; Accepted: October 1, 2001

Proofs received from author(s): November 25, 2001 